\title{
RELEVANSI AJARAN TASAWUF BAGI KEHIDUPAN MUSLIM DI ERA MODERN
}

\author{
Puthut Waskito \\ STAI, Madiun, Indonesia \\ Puthut.waskito86@gmail.com \\ DOI: 10.20885/tarbawi.vol14.iss1.art1
}

\begin{abstract}
This research is based on the fact that materialistic culture is in rise and spread across Muslim society. Almost all aspects of life are judged only by material measures. On that basis, the author sees the relevance of Sufi teachings. This research is conduct through library research methode. The primary data sources in this study are Sufi literature and the social condition of Muslim community. The secondary data sources were obtained from several writings from Sufis observer and the results of Sufi practitioners in alleviating various problems and providing various solutions to the society. The results of this study indicate that the morals of Sufism as exemplified by the Prophet Muhammad are very relevant if applied to the current modern era. In addition, various ahwal conditions or spiritual conditions such as qurbah, khauf and raja' can contribute to peace of mind and human peace in everyday life in today's modern era. Especially it can reduce the condition of the soul which always refers to the aspect of materialism which is only focused on outward needs
\end{abstract}

Keywords: Sufism teaching; Noble character; Materialism; Modern Era. 


\title{
$e^{\text {I-Tarbawj Puthut Waskito }}$
}

\begin{abstract}
Abstrak
Penelitian ini dilatarbelakangi oleh budaya materialistik yang marak dan menjamur di lingkungan masyarakat muslim. Hampir semua aspek kehidupan dinilai hanya pada ukuran material. Atas dasar itu, penulis melihat relevansi ajaran tasawwuf. Penelitian ini menggunakan jenis metode penelitian pustaka. Adapun sumber data primer dalam penelitian ini berhubungan dengan literatur sufi dan kondisi sosial masyarakat muslim. Adapun sumber data sekunder diperoleh dari beberapa tulisan para pengkaji ilmu tasawuf serta hasil para praktisi tasawuf di lapangan dalam mengentaskan berbagai masalah dan memberikan berbagai solusi kepada masyarakat umum. Hasil penelitian ini menunjukkan bahwa akhlak tasawuf sebagaimana dicontohkan oleh Rasulullah Saw sangat relevan jika diterapkan pada era modern saat ini. Selain itu berbagai kondisi ahwal atau kondisi spiritual seperti qurbah, khauf dan raja' dapat memberikan kontribusi bagi ketenangan jiwa dan ketentraman manusia dalam kehidupan sehari-hari pada era modern saat ini. Terutama dapat menguragi kondisi jiwa yang selalu mengacu pada aspek materialisme yang haya tertuju pada kebutuhan lahiriah semata.
\end{abstract}

Kata Kunci: Ajaran Tasawuf; Akhlak Mulia; Materialisme; Masa Modern. 


\section{Pendahuluan}

Modernisasi dalam pelbagai aspek kehidupan masyarakat memiliki dua dampak. Di satu sisi, modernisasi yang berwujud pada perkembangan ilmu pengetahuan dan teknologi, khususnya teknologi digital, banyak memberikan kemajuan dan kemudahan bagi manusia. Di sisi yang lain, pada aspek mentalitas, moralitas dan spiritual, modernitas membawa ekses-ekses negatif bagi kehidupan masyarakat.

Pada ranah moralitas, masyarakat muslim dihadapkan pada era baru di mana nilai-nilai yang selama ini diyakini mengalami perubahan. Baik dalam bidang pendidikan, ekonomi, kehidupan sosial masyarakat, bahkan pola pendidikan keluarga. Modernitas menimbulkan tumbuh suburnya cara pandang materialisme di kalangan masyarakat.

Dampak dari cara pandang materialisme ini dapat kita lihat di mana-mana. Hampir semua aspek kehidupan diukur dengan tolak ukur materi. Pada aspek pendidikan misalnya, pendidikan formal diarahkan pada orientasi dunia. Akibatnya orientasi ini, banyak anak-anak muda setelah lulus menjadi sarjana megalami stres berat, bahkan tidak sedikit yang mengalami gangguan jiwa bila tidak mendapatkan pekerjaan.

Dari aspek ekonomi, banyak keluarga baru bangkrut karena menjadikan hedonisme sebagai gaya hidup atas dasar gengsi. Dampaknya adalah keretakan keluarga dan korbannya adalah anak-anak yang tidak berdosa. Pada akhirnya banyak anak tidak mendapatkan pendidikan layak dan baik dari 


\section{$e^{\text {I-Tarbawj Puthut Waskito }}$}

keluarga maupun dari lembaga pendidikan formal. Dari semua itu dapat kita rasakan secara langsung imbas berupa merosotnya moral dan ilmu pengetahuan di dalam masyarakat.

Modernitas juga membuat minat belajar anak-anak muda menurun karena pengaruh dunia maya. Game online menjadi candu bagi kalangan muda.. Bahkan situs-situs berbau pornografi secara bebas dapat diakses secara mudah oleh remaja pada saat ini. Berbagai hal diatas merupakan dampak yang nyata dan dapat kita rasakan secara langsung dalam kehidupan sehari-hari.

Dari pada itu, maka pencerahan ruhani perlu digalakkan dan dikembangkan kembali di tengah kehidupan masyarakat luas. Sejatinya, aspek jasmani selalu berdampingan dengan sisisisi ruhani. Akan tetapi di masa modern ini, agama banyak diterapkan hanya dalam bentuk aturan formal saja (Mannan, 2018). Penyegaran dalam bidang agama juga perlu dikaji kembali, sehingga tidak pada ranah lahiriah belaka. Sisi-sisi ruhani perlu ditonjolkan dan dijabarkan secara terbuka pada khalayak umum sehingga masyarakat muslim tidak jenuh hanya berkutat pada tataran jasmani.

Penelitian ini berusaha menjelaskan fenomena tersebut untuk menjelaskan relevansi tasawuf. Tasawuf sebagai ajaran dan warisan para nabi dapat menjadi sebuah obat yang mujarab bagi penyakit yang dialami masyarakat modern pada saat ini. Sentuhan-sentuhan ajaran tasawwuf bagaikan madu yang dapat digunakan sebagai obat bagi berbagai penyakit. 
Para sufi menyebutkan bahwa tasawuf adalah jalan penyucian hati dan jiwa yang dapat digunakan sebagai kunci utama dalam menyelesaikan permasalahan kehidupan. Selain itu dalam tasawwuf dijelaskan berbagai penyakit hati dan jiwa yang muncul dari pikiran yang kotor sehingga memberikan dampak negatip pada perilaku seseorang.

Dalam tulisan ini, penulis akan memaparkan tentang hakikat tasawuf, serta beberapa ajaran tasawuf yang dapat diaplikasikan secara langsung dalam kehidupan sehari-hari, guna menyikapi kehidupan pada zaman modern saat ini.

\section{Metode Penelitian}

Penelitian ini termasuk dalam jenis penelitian pustaka (library research) yakni penelitian yang bertujuan untuk mengumpulkan data yang berasal dari penelusuran dan penelaahan literatur melalui berbagai sumber data primer dan beberapa sumber data sekunder. Pengumpulan data dilakukan dengan mengutip sumber data berupa data primer dan data sekunder. Adapun sumber data primer berhubungan dengan literatur ilmu-ilmu tasawwuf serta melihat seting kondisi sosial masyarakat beserta berbagai problemnya. Adapun sumber data sekunder diperoleh dari beberapa tulisan para pengkaji ilmu tasawwuf serta hasil para praktisi tasawwuf di lapangan dalam mengentaskan berbagai masalah dan memberikan berbagai solusi kepada masyarakat umum. 


\section{$e^{\text {I-Tarbawj Puthut Waskito }}$}

\section{Hasil dan Pembahasan}

\section{Hakikat Tasawuf}

Pada hakikatnya, tasawuf merupakan syariat Islam yang berhubungan dengan aspek batin dari ajaran agama. Tasawuf merupakan upaya pembersihan jiwa (takiyatu al-nasf) untuk memusatkan perhatian kepada Allah Swt semata (Badrudin, 2015: 1). Pada praktiknya, ia memuat metode-metode yang bermacam-macam, seperti perbaikan akhlak, kontemplasi, riyadlah, untuk mencapai tujuan di atas berdasarkan kemampuan dan kecenderungan masing-masing individu (Mashar, 2015: 101).

Ketika manusia diturunkan di alam mitsal yakni dunia fana' ini, banyak yang tergoda dan lupa akan hakikat keberadaan ruh suci. Banyak yang gila kepada dunia karena jiwanya buta, tuli dan bisu karena tidak pernah melihat alam kesejatian. Hidupnya hambar, linglung tidak karu-karuan. Berjalan seperti manusia tetapi jiwanya seperti hewan melata, bimbang jalannya, gelap mata batinnya (Puthut Waskito, 2012: 23). Begitu kondisi jaman edan yang kita jumpai pada saat ini. "Sak bejo-bejone wong urep ing jaman edan iseh bejo wong kang eleng lan waspodo," demikian pepatah jawa mengungkapkan. Bukan jamannya yang gila, tapi jiwanya yang gila karena mengikuti hawa yang ada dalam hati sanubari sehingga gelap hidupnya (Puthut Waskito, 2015: 33). 
Roh kudus yang ditiupkan pada hati rohani bertugas hanya untuk menyembah Dzat Allah Swt. Terus menerus tanpa putus, bersama setiap tarikan dan hembusan nafas, dan inilah yang disebut dengan dzikir daim. Dzikir daim yang dilakukan secara sirri di dalam hati setiap insan, para wali mengatakan pada "telenging manah" yakni pada pusatnya hati (Purwadi, Siti Maziyah, 2005:45). Syekh Abdul Qodir Al-Jilani menjelaskan bahwa dzikir sirri ini sebagaimana diperintahkan Allah Swt dalam Al-Qur'an yang bermakna "dan jagalah shalat wustha," yakni shalat yang di dalam hati, shalatnya hati, shalat yang abadi tidak terikat waktu. Karena hati diciptakan di tengahtengah jasad antara kanan dan kiri, atas dan bawah dan diantara bahagia dan celaka.

Adapun Sunan Kalijaga dalam Kitab Dzuriyat menjelaskan terkait $d z i k i r$ daim yakni:

"Nyatane sholat daim (dhiker daim) iku ratu-ratuning shalat, punjul-punjuling sembahyang, awit langgeng penelangsane maring Pengeran, tanpo pedot ing rino wengi, nadyan ora nganggo sujud rukok, wus kukoh, nadyan turu utowo meneng, lunggoh lumaku, iyo wus ono siro puji dhikire, sujud rukue, iyo iku umpomo wong ambalang melek cedak elesane, wallahu aklam, luputo pangarahe, mesti kenane".

Maka sebutlah dan ingatlah Allah Swt di dalam hatimu dengan ingatan sebanyak-banyaknya. Karena Allah Swt bersama hamba-hamba-Nya yang selalu mengingat-Nya. Bagi yang dapat melaksanakannya, dialah yang disebut dengan manusia berjiwa kesatria yang dinyatakan sebagai kesatria 


\section{$e^{\text {I-Tarbawj Puthut Waskito }}$}

lelanange jagad kang tanpo cacat (Imam Isfandi, 1992: 16). Yakni manusia yang melaksanakan perintah Tuhan-Nya dalam melanggengkan dzikir isim ghaib. Qul hu Allahu Ahad. Nyatane mung sang Kholik kang diroso, ngrasa keno diarani panggah manggon. Sehinga barang siapa yang diijinkan oleh Allah Swt untuk diwenangkan dalam rasa kesejatian isim ghaib Allah yakni " $h u$ ", dapat dikatakan telah menetapi jiwa satria.

Pernyataan di atas sebagaimana sabda Nabi Muhammad Saw yang diriwayatkan dari Ali karamallahu wajhah: "Ana madinatul 'ilmi wa'aliyun babuhaa," yang berarti aku kotanya ilmu dan Ali adalah pintunya (Imam Isfandi, 1992: 18). Terkait " $h a$ " ini pada awalnya, Imam Ali bertanya pada Rasulullah Saw sebagaimana berikut:

"Ya Rasulullah, dallani 'alaa aqrabi thuruqin ilallahi wa ashalihaa 'alaa 'ibadihhi waafdhalihaa 'indaallah."

Yang artinya, wahai Rasulullah tunjukkanlah padaku atas jalan yang paling dekat kepada Allah Swt dan yang paling mudah bagi hamba-Nya dan yang paling utama bagi Allah Swt. Kemudian Rasulullah Saw menjawab:

"Ya 'Ali, fadawwim 'ala dzikrillahii sirran au jahran."

Yang artinya, wahai Ali, langgengkanlah dalam berdzikir mengingat Allah Swt secara tersembunyi maupun secara lantang. Kemudian Sayyidina Ali Ra berkata kepada Rasulullah Saw:

"Kullu annasi dzaakiriina walakin uridu an tuhshani bisyai'in yaa Rasulallah." 
Yang artinya, semua manusia berdzikir mengingat Allah Swt, tetapi saya ingin Rasulullah menunjukkan kepadaku dengan sesuatu wahai Rasulullah.

Dalam riwayat tersebut, Rasulullah Saw kemudian menjelaskan sesungguhnya dzikir itu ada tujuh macam: 1. Nafi isbat ucapannya la ilaahaillallah, 2. Dzikir isbat ucapane illallah, 3. Dzikir isim Dhat ucapannya Allah, 4. Dzikir taraqi ucapannya Allah-hu, 5. Dzikir tanazul ucapannya Hu-Allah, 6. Dzikir isim ghaib ucapannya $H u, 7$. Dan yang ketujuh tidak dapat mengerti kecuali telah diajar oleh seorang guru sejati (Imam Isfandi, 1992: 19).

\section{Pengertian Tasawuf Menurut Para Sufi}

Secara bahasa, menurut al-Hujwiri seperti dikutip Maisyaroh (2014: 142), kata tasawuf dapat berasal dari empat istilah etimologis, yaitu shuf (pakaian wol), shafa' (suci), ahlu shufah (sahabat Nabi yang tinggal di halaman masjid Nabawi) dan shaf (barisan).

Sementara itu, para sufi memiliki pendapat yang unik dalam memaknai tasawuf. Mereka memahami tasawuf sebagai ajaran yang bersifat praktik bukan hanya ranah teoritik. Mereka tidak hanya menjabarkan tasawuf dari segi bahasa yang terasa kering jika diresapi oleh hati Nurani (Abu Nashr as-Sarraj, 2002: 45). Pelaksanaan ajaran tasawuf secara nyata memberikan cita rasa yang khas bagi para sufi dalam memaknai ajaran tasawuf yang mereka laksanakan secara turun-temurun dan 


\section{$e^{\text {I-Tarbawj Puthut Waskito }}$}

berpenghujung pada baginda Nabi Muhammad Saw. Hal ini dapat kita lihat dari pernyataan para sufi ketika mereka menjelaskan apa sebenarnya ajaran tasawwuf (Asrifin, 2001: 3).

Salah satu sufi terkemuka yakni Syekh Junaid Al-Bagdadi yang terkenal dijuluki sebagai thawusul ulama' (meraknya para ulama) menyatakan bahwa tasawuf adalah ketika engkau bersama Allah Swt tanpa perantara (Abu Nashr as-Sarraj, 2002: 53). Maka ada beberapa aulia dan khawasul khawas menyatakan bahwa seorang mursyid mendampingi seorang murid atau seorang salik hanya sampai alam jabarut, di atasnya alam jabarut harus ditempuh sendirian sehingga hanya dia sang salik dan Allah Swt. Maka ketika Syekh Junaid Al-Baghdadi ditanya mengeni tasawuf, beliau menyatakan sebagaimana tadi yakni bahwa tasawuf adalah ketika engkau bersama Allah Swt tanpa perantara. Kemudian Syekh Muhammad Al-Khossab guru dari Syekh Junaid Al-Baghdadi menyatakan bahwa tasawuf adalah akhlak mulia yang muncul pada zaman yang mulia dari orangorang yang mulia kemudian dilakukan oleh kaum atau orangorang yang mulia (Abu Nashr as-Sarraj, 2002: 53). Hal ini berkaitan erat dengan apa yang telah penulis sampaikan pada penjelasan sebelumnya bahwa ilmu tasawuf ini diajarkan oleh Rasulullah Saw pada beberapa sahabat beliau dan yang paling mashur adalah Sayyidina Ali Ra sebagai mana penulis jabarkan di atas. Dari sahabat Ali bin Abi Thalib Ra ini muncul hampir empat puluh lebih tarekat besar yang menyebar keseluruh penjuru dunia. 
Selanjutnya tasawuf menurut Syekh Ruwaim adalah lepasnya jiwa seseorang kemudian jiwa tersebut bersama Allah dan sesuai dengan kehendak Allah Swt. Ungkapan ini sesuai dengan apa yang disampaikan oleh Syekh Abu Hasan AsSyadhili ketika beliau berada di Mesir beliau berkata, "ana wa anta fi Qabdillah," yang artinya aku dan engkau berada dalam genggaman Allah Swt dalam artian dalam kuasa Allah Swt. Kemudian menurut Syekh Hamzah, tasawuf adalah ketika engkau tidak merasa memiliki apa-apa dan tidak merasa dikusai apa-apa. Maksud dari hal ini adalah tidak merasa memiliki hal-hal yang bersifat duniawi dan tidak merasa dibelenggu oleh urusan-urusan yang bersifat materi atau duniawi. Jika dikaji secara teliti dari sudut pandang praktisi tasawuf, apa yang dijelaskan Syekh Hamzah tersebut mengindikasikan ketika seorang salik dalam keadaan fana billah. Kemudian, menurut Syekh Jarir, tasawuf adalah ketika engkau masuk pada perilaku yang baik atau akhlak yang baik dan ketika engkau keluar dari perilaku yang tercela (Abu Nashr as-Sarraj, 2002: 53). Kemudian menurut seorang wali lain, tasawuf adalah ketika engkau meyebarkan berbagai kondisi spiritual dan berbagai kedudukan spiritual kemudian engkau tetap istiqamah dalam hal itu dan secara terus menerus tersambung kepada Allah Swt. Demikian berbagai pendapat dan pengertian tasawuf menurut para praktisi sufi. 


\section{$e^{\text {I-Tarbawj Puthut Waskito }}$}

\section{Akhlak Mulia dalam Tasawuf}

Akhlak adalah ilmu untuk bertindak atau pengetahuan tentang hal-hal yang menunjukkan kepada manusia jalan yang baik untuk dapat hidup dalam masyarakat (Tim Penulis, 1996: 271). Akhlak juga disebut dengan budi pekerti, etika atau moral. Akhlak atau budi pekerti di sini adalah akhlak yang berhubungan erat dengan agama dan sangat perlu untuk dimiliki oleh insan yang akan hidup berdampingan dengan sesamanya di dalam masyarakat (Tim Penulis, Imam Zarkasyi, 1996: 274). Sebagaimana kita ketahui, dalam agama Islam, akhlak merupakan hal yang sangat penting. Bahkan dalam AlQur'an disebutkan:

"Dan Sesungguhnya kamu benar-benar berbudi pekerti yang agung. (QS: Al-Qalam: 4).

Akhlak merupakan petunjuk dan pedoman yang harus diikuti dan dilaksanakan dalam kehidupan sehari-hari. Akhlak dibagi menjadi dua bagian penting, yakni akhlak lahir dan akhlak batin. Akhlak lahir terdiri dari gerak gerik, tingkah laku, pakaian, perkataan, penampilan dan lain-lain. Akhlak batin terdiri hal-ihwal yang berkenaan dengan kondisi jiwa, sifatsifat terpuji, adab dalam beribadah, tata krama dan masih banyak lagi (Imam Zarkasyi, tt: 16). Pembinaan akhlak lahir maupun batin merupakan salah satu prioritas utama tasawuf. Dalam sebuah hadis Rasulullah Saw bersabda, "addabani rabbi fa ahsana $t^{\prime}$ dibi" kemudian beliau juga menyatakan dalam hadis 
yang diriwayatkan Imam Ahmad "innama buistu liutammima makarima al-akhlaq.". Dalam sebuah hadis lain, Rasulullah Saw mengatakan "ma nakala walidun waladan illa min adabin hasanin," yang bermakna bahwa tidak ada pemberian orang tua kepada anaknya yang lebih utama dari pada adab yang baik (Abu Nashr as-Sarraj, 2002: 303). Maka jelas bagi kita sebagai seorang muslim bahwa adab menempati posisi yang sangat penting dalam kehidupan sehari-hari.

Dalam tasawuf, akhlak al-karimah menempati kedudukan yang sangat tinggi dan sangat penting selain ilmu itu sendiri. Karena dengan adab yang baik, hati bisa menjadi baik dan lunak. Adab yang baik juga dapat menjadi sebuah perantara bagi terangkatnya lapisan-lapisan hijab yang ada pada hati sanubari, hati nurani dan hati rohani kemudian hati sirri sehingga Allah Swt memberikan pencerahan ruhani. Maka tidak heran jika banyak wali menyatakan bahwa mereka lebih membutuhkan adab yang baik meskipun sedikit dibandingkan dengan ilmu yang sangat banyak tetapi tidak disertai dengan adab yang baik. Oleh karena itu, para sufi selalu mengajarkan dan memerintahkan pada para murid untuk selalu menepati dan melaksanakan adab-adab yang baik kepada Allah Swt kemudian kepada Nabi Muhammad Saw dan keluarganya kemudian adab kepada sesama manusia dan adab kepada semua makhluk. Adab-adab tersebut melingkupi sisi lahir maupun batin. 


\section{$e^{\text {I-Tarbawj Puthut Waskito }}$}

Sebagai contoh, kita dapat menyaksikan apa yang telah dilaksanakan oleh guru tarekat yakni Syekh Abu Hasan AsSyadhily. Dalam hal adab kepada guru, beliau telah memberikan contoh bahwa seorang murid hendaknya selalu mengosongkan diri dan tidak menyombongkan ilmunya pada seorang guru rohani. Hal ini dilakukan beliau ketika beliau hendak berguru kepada Syaikh Ahmad Al-Basys. Ketika Syekh Abu-Hasan As-Syadhily mengetahui gurunya berada di atas sebuah gunung, maka beliau segera berangkat menuju tempat tersebut. Kemudian ketika beliau telah berada di kaki gunung, beliau mandi di sebuah sungai kemudian berdo'a seraya melepas semua keilmuannya sebagai rasa hormat kepada Syekh Al-Basys. Setelah itu beliau naik dan bertemu dengan Syekh Al-Basys kemudian gurunya berkata, "Wahai Abu Hasan! Sudah benar yang Engkau lakukan, Engkau menanggalkan seluruh ilmu pengetahuanmu di bawah lembah." Kemudian beliau membacakan nasab Syekh Abu Hasan As-Syadhily sampai pada Rasulullah Saw dan kemudian menerimanya sebagai murid.

Hal serupa juga dilakukan oleh Syekh Bahauddin AnNaqsabandi ketika beliau ber-tawajjuh dihadapan Syekh Abdul Kholiq Gujhnawandy. Meskipun Syekh Abdul Khaliq Gujhnawandy telah meninggal dunia dan berjarak sekitar 200 tahun dengan Syekh Bahauddin An-Naqsabandy, tetapi beliau tetap melaksanakan adab-adab seorang murid kepada gurunya yang masih hidup di depan makam beliau. Adab-adab yang 
baik atau akhlak al-karimah selalu menempati posisi utama dalam segala aspek kehidupan para sufi. Mereka selalu mengimbangi ilmu dengan akhlak al-karimah, karena adab yang baik meskipun sedikit lebih utama dibandingkan dengan ilmu yang banya tetapi tidak disertai dengan adab yang baik.

Contoh-contoh akhlak mulia dari para sufi tadi menegaskan bahwa tasawuf merupakan nafas dari ajaran agama Islam. Demikian karena pada hakikatnya, semua hukum Islam memiliki landasan akhlaknya (Mannan, 2018: 44).

Perilaku atau penerapan akhlak al-karimah kesufian ini dapat pula secara langsung diajarkan dan diimplementasikan bagi kehidupan masarakat luas. Perlu dipahami, bahwa akhlak al-karimah tersebut mencakup sisi lahir maupun batin sebagaimana telah dicontohkan oleh Rasulullah Saw (Abu Nashr as-Sarraj, 2002: 27).

\section{Kondisi Spiritual dalam Tasawwuf}

Sebagaimana kita ketahui bersama bahwa ahwal atau kondisi spiritual, atau kejiwaan seorang salik dalam perjalanan mengarungi dunia kesufian memiliki pengaruh yang sangat kuat bagi perilaku seorang salik dalam kehidupan nyata di dalam masyarakat. Kondisi spiritual tersebut merupakan pemberian dari Allah Swt melalui penyucian jiwa (Asnawiyah, 2014: 83).

Dari berbagai kondisi spiritual tersebut ada beberapa sikap dan kondisi kejiwaan tasawuf yang dapat diterapkan oleh 


\section{$e^{\text {I-Tarbawj Puthut Waskito }}$}

setiap individu dalam kehidupan, khususnya pada era modern. Hal tersebut dalam rangka memberikan ketenangan jiwa dan kestabilan dalam menjalani kehidupan yang serba modern pada saat ini sehingga ketenangan dan kedamaian jiwa dapat tercapai. Adapun beberapa kondisi spiritual dalam tasawuf yang dapat diterapkan adalah sebagai mana berikut:

1. Qurbah

Qurbah adalah kedekatan dengan Allah Swt, kondisi spiritual yang mulia, yang menyebabkan hati setiap hamba selalu merasa tenang dan tentram karena Allah Swt selalu menyertainya (Abu Nashr as-Sarraj, 2002: 115). Semua permintaan dan keinginan hanya akan ditujukan pada Allah Swt semata. Pencapaian-pencapaian dalam kehidupan tidak selalu mengandalkan dari hasil upaya dan jerih payah manusia karena pada hakikatnya hanya Allah-lah yang menentukan. Dalam al-Qur'an, Allah Swt berfirman yang artinya:

“Dan apabila hamba-hamba-Ku bertanya kepadamu tantang $\mathrm{Aku}$, maka (jawablah) bahwa sesungguhnya Aku adalah dekat." (QS. Al-Baqarah: 186).

Kemudian Allah Swt juga berfirman yang artinya:

"Dan sesungguhnya Kami telah menciptakan manusia dan mengetahui apa yang dibisikkan kepadanya oleh nafsunya dan Kami lebih dekat kepadanya daripada urat lehernya." (QS. Qaaf: 16).

Sebagaimana kita ketahui dan sebagaimana dinyatakan oleh para sufi bahwa kondisi spiritual qurbah atau kedekatan 
pada Allah Swt selalu beriringan dengan kondisi spiritual mahabbah atau rasa cinta serta khauf atau rasa takut. Kondisi spiritual ini menjadikan hati seorang hamba selalu merasa dekat dan diawasi oleh Allah Swt sebagaimana disebutkan pada ayat di atas (Abu Nashr as-Sarraj, 2002: 117). Kedekatan itu adalah menyadari bahwa Allah Swt mengetahui semua dan apa saja yang ada dalam hati manusia bahkan apapun yang dibisikkan oleh nafsu pada hati manusia (Farhad dan Farouk, 2015: 37). Selain itu perasaan dekat setiap hamba kepada Allah Swt menjadikan semua permintaan hanya akan diutarakan dan dimintakan kepada Allah Swt, tidak kepada selain Allah Swt. Dengan demikian setiap usaha tidak akan selalu disandarkan pada dirinya sendiri dan secara sadar semua keinginan dan permintaan baik secara lahiriah maupun batiniah akan selalu disandarkan hanya kepada Allah Swt.

Kondisi spiritual yang diraih dalam qurbah ini, pada hakikatnya, merupakan intisari dari ajaran tasawuf. Karena dalam tasawuf, tujuan yang ingin dicapai adalah hubungan langsung dengan Tuhan (Nilyati, 2015).

2. Khauf dan Raja'

Rasa dekat kepada Allah memunculkan rasa cinta kepadaNya serta rasa cinta memunculkan rasa takut (khauf) dan harapan (raja') kepada Allah Swt. Tanpa adanya rasa takut seorang hamba pada Tuhannya, maka manusia akan cenderung untuk melanggar berbagai perintah dan larangan-Nya. Adapun rasa takut kepada Allah Swt dibedakan menjadi tiga macam. 


\section{$e^{\text {I-Tarbawj Puthut Waskito }}$}

Pertama, sebagaimana Allah menyebutkan dalam sebuah Surat Ali Imran ayat 175 yakni rasa takut yang dibarengi dengan keimanan (Abu Nashr as-Sarraj, 2002: 123). Sebagaimana firman-Nya:

"Oleh karena itu, janganlah kalian takut pada mereka tetapi takutlah pada-Ku, jika kalian benar-benar orang beriman." (QS. Ali Imran: 175).

Sebagaimana disebutkan dalam ayat tersebut, rasa takutnya orang-orang mulia yang memiliki kedudukan yang tinggi di sisi Allah Swt. Kemudian Allah juga berfirman:

"Dan bagi orang yang takut akan saat menghadap Tuhan-nya ada dua surga (untuk manusia dan jin). (QS. Al-Rahman: 46).

Adapun yang disebutkan pada ayat tersebut, adalah takut jenis kedua, yaitu takutnya orang-orang golongan menengah. Selanjutnya Allah juga berfirman:

Mereka takut pada suatu hari (dimana pada hari itu) hati dan penglihatan menjadi goncang. (QS. An-Nur: 37).

Adapun yang disebutkan oleh ayat ini adalah takutnya orang-orang golongan awam (Abu Nashr as-Sarraj, 2002: 124). Sehingga jika diurutkan maka takutnya orang-orang awam adalah karena siksa dan hukuman dari Allah Swt sedangkan takutnya orang-orang golongan menengah adalah dikarenakan takut akan terputusnya hubungan mereka dengan Allah Swt dan yang terakhir takutnya golongan khusus yakni orangorang yang mulia derajatnya adalah hanya takut kepada Allah Swt semata. Dari ketiga tingkatan rasa takut tersebut, dapat 
kita ambil dan teladani sesuai dengan kemampuan masingmasing.

Selanjutnya adalah raja' atau rasa penuh harap yang mana ini adalah salah satu kondisi spiritual yang mulia. Allah Swt berfirman dalam Al-Qur'an sebagaimana berikut:

"Barang siapa berharap untuk bertemu Tuhannya maka hendaklah ia beramal saleh dan tidak mempersekutukan dengan seorang pun dalam beribadah kepada Tuhannya." (QS. AlKahfi: 110).

Adapun raja' dibagi menjadi tiga tingkatan. Pertama, berharap akan pahala Allah Swt yang demikian itu adalah harapan orang-orang umum. Kemudian harapan orang-orang golongan menengah yakni berharap akan keluasan rahmat Allah Swt. Sedangkan orang-orang yang ditinggikan derajatnya mereka hanya berharap akan Allah Swt semata tidak pada yang lainnya. Aktualisasi secara hakiki dari seorang hamba adalah ketika ia hanya berharap kepada Allah Swt semata dalam semua aspek kehidupannya (Abu Nashr as-Sarraj, 2002: 127).

Dari kedua kondisi spiritual tersebut seorang hamba dapat lebih berhati-hati dalam melaksanakan berbagai kegiatan di dalam lingkup masyarakat luas. Karena dengan adanya rasa takut kepada Allah Swt seorang hamba akan lebih berhati-hati dalam berbuat dan berperilaku serta hatinya hanya berharap pada Allah Swt semata tidak ada harapan kepada selain Allah Swt. Demikian itu akan menjadikan jiwa dan pikiran seorang 


\section{$e^{\text {I-Tarbawj Puthut Waskito }}$}

hamba tenang dan tentram dalam mengarungi bahtera kehidupan di dunia ini secara lahir dan batin.

\section{Kesimpulan}

Kehidupan modern meskipun membawa kemajuan bagi umat manusia tetapi juga memiliki dampak negatif. Di antaranya adalah perubahan nilai-nilai moralitas dan spiritual akibat merebaknya cara pandang materialisme. Pada dasarnya, tasawuf sebagai bagian dari syariat Islam yang mengatur tentang metode penyujian jiwa dapat menjadi solusi atas permasalahan tersebut.

Praktik tasawuf di dalamnya terdapat berbagai suri tauladan yang baik. Semua akhlak al-karimah dalam tasawuf dilaksanakan sesuai dengan petunjuk dan arahan dari Rasulullah Saw baik secara lahir maupun secara batin. Semua adab dalam bidang syariat maupun dalam bidang hakikat dilaksanakan sesuai contoh dan tauladan yang telah diberikan oleh Rasulullah Saw dengan selalu berpegang teguh pada AlQur'an dan As-Sunnah. Terakhir sikap dan kondisi spiritual dalam tasawuf dapat menjadi solusi bagi permasalahan kehidupan manusia pada era modern saat ini. Salah satunya adalah kondisi spiritual qurbah atau merasa dekat dengan Allah Swt yang secara otomatis akan menjadikan seorang hamba selalu merasa diawasi oleh Allah Swt dan memanjatkan semua do'a dan permintaanya hanya kepada Allah Swt semata. 
Relevansi Ajaran Tasawuf... el-Tarbawj

Selanjutnya adalah khauf dan raja' yang akan menjadi benteng bagi setiap orang untuk selalu waspada dalam melaksanakan perintah dan larangan-Nya serta hanya berharap pada Allah Swt baik semua keperluanya yang bersifat lahiriah maupun batiniah. Hal-hal di atas jika dapat diaplikasikan dalam praktik kehidupan sehari-hari maka akan memberikan ketenangan jiwa dan mengurangi berbagai permasalahan dalam kehidupan sehari-hari. 


\section{$e^{\text {I-Tarbawj Puthut Waskito }}$}

\section{Daftar Pustaka}

As-Sarraj, Abu Nashr. 2002. Al-luma' Rujukan Lengkap Ilmu Tasawwuf. Surabaya: Risalah Gusti.

Asnawiyah. 2014. Maqam dan Ahwal: Makna dan Hakikatnya dalam Pendakian Menuju Tuhan. Substantia, Vol. 16 (1), hal. 79-86.

Asrifin. 2001. Jalan Menuju Ma'rifatullah dengan Tahapan 7 M. Surabaya: Terbit Terang.

Badruddin. 2015. Pengantar Ilmu Tasawuf. Serang: Penerbit A 4.

Isfandi, Imam. 1992. Al-Haqqu Haadzal Kitab. Ngawi: Jama'ah Sathoriyah.

Zarkasyi, Imam. Tanpa Tahun. Cara Mengisi Kekosongan $\mathcal{E}$ Etiquette Adat Sopan Santun. Ponorogo: Darusssalam Press.

Maisyaroh. 2014. Tasawuf sebagai Dimensi Batin Ajaran Islam. Jurnal At-Tafkir, Vol. 8 (2), hal. 141-151.

Mannan, Audah. 2018. Esensi Tasawuf Akhlaki di Era Modernisasi. Jurnal Aqidah-ta, Vol. 6 (1), hal. 36-56.

Mashar, Aly. 2015. Tasawuf: Sejarah, Madzhab dan Inti Ajarannya. Al-A'raf: Jurnal Pemikiran Islam dan Filsafat, Vol. 12 (1), 97-117.

Farhad, Muhammad dan Farouk, Abdullah. 2015. Khutbah Jum'at Membangun Moralitas Umat. Surabaya: Amelia.

Nilyati. 2015. Peranan Tasawuf dalam Kehidupan Modern. Tajdid, Vol. 14 (1), hal. 119-142. 
Relevansi Ajaran Tasawuf... el-Tarbawj

Purwadi dan Maziyah, Siti. 2005. Hidup dan Spiritual Sunan Kalijaga. Yogyakarta: Tunas Harapan.

Waskito, Puthut. 2012. Suluk Lintang Kolo Sekti. Yogyakarta: Giri Suci Waris Mataram.

Waskito, Puthut. 2015. Suluk Wahdat. Ponorogo: Puser Bumi.

Tim Penulis. 1996. K.H. Imam Zarkasyi Dari Gontor Merintis Pesantren Modern. Ponorogo: Gontor Press. 